\title{
Going Global: The Successful Link of IELTS and Aptis to China's Standards of English Language Ability (CSE)
}

\author{
Xueliang $\mathrm{Chen}^{1} \&$ Jie $\mathrm{Hu}^{1}$ \\ ${ }^{1}$ Department of Linguistics, School of International Studies, Zhejiang University, Hangzhou, Zhejiang, China \\ Correspondence: Jie Hu, Department of Linguistics, School of International Studies, Zhejiang University, \\ Hangzhou City, Zhejiang Province, 310058, China. E-mail: huj@zju.edu.cn
}

$\begin{aligned} & \text { Received: August 24, } 2020 \\ & \text { Accepted: October 10,2020 Online Published: October 29, } 2020 \\ & \text { doi:10.5539/ijel.v11n1p1 }\end{aligned}$ URL: https://doi.org/10.5539/ijel.v11n1p1

\begin{abstract}
The development of a common language proficiency scale is essential to language teaching, learning, and assessment. While some general English proficiency scales already exist, no such scale is available in an Asian context. China's Standards of English Language Ability (CSE), as the first scale of its kind, promises to address this deficiency with a clear focus on the student population, grounded in the well-established framework of communicative language ability. As such, it not only illuminates the learning patterns of English language learners at different stages, but also provides a benchmark for curriculum design, student evaluation, and the improvement of educational programs. More importantly, its recent link with such international tests as Aptis and IELTS marks a significant step towards the internationalization of this scale, making student grades on different tests more comparable. The official mapping of CSE to the international examination system opens China's education further to the rest of the world, and would facilitate student exchanges and deepen educational ties between countries in the future.
\end{abstract}

Keywords: Aptis, China's standards of English language ability, IELTS, language assessment

\section{Introduction}

English as a foreign language (EFL) education has played a prominent role in China's academic and social life since the country restored its university matriculation examination system in the late 1970s. For decades, efforts to promote English language learning, teaching, and assessment in China have been made at the individual, societal, and governmental levels, exemplified by the numerous training centers established, the status assigned to English as a compulsory course in secondary-level and tertiary-level education, and the miscellaneous tests devised as measures of students' English language ability (Chen \& Hu, 2020; Qian \& Cumming, 2017; Xiao, Liu, $\& \mathrm{Hu}, 2019)$. In many ways, achieving a certain level of English proficiency is perceived not only as the mastery of an essential communicative skill, but also as a ladder of opportunity and upward mobility in an increasingly globalized world (Bolton \& Graddol, 2012; Chen \& Hu, 2019; Hu, 2014). Currently, China boasts the largest number of English language learners in the world (Kunnan, 2014). In their experiences of English language learning, they are often compelled to take high-stakes tests in order to enter or complete educational programs, which inevitably will have consequential implications for their study and careers (Chen, Zhang, \& Hu, 2020; Chen, Zhang, Wei, \& Hu, 2019; Cheng \& Curtis, 2010).

Among the most influential English language tests in China are the National Matriculation English Test (NMET) for secondary school graduates, the College English Test (CET) series (CET Band 4 and CET Band 6), and the Test for English Majors (TEM) series (TEM Grade 4 and TEM Grade 8), which are all administered on a national basis. These do not even include tests that are designed for individual purposes and at institutional levels, or those purely introduced from abroad, such as IELTS, TOEFL and GRE. Without a comprehensive and coherent framework for streamlining the examination process at different stages of English language learning (Cheng \& Curtis, 2010; Hu, Chen, \& Liu, 2020; Hu \& Wei, 2019), this wide array of tests has led to great confusion in China's education market and carry many potential problems.

Amid growing awareness of this problem and an urgent call for rectification, China launched an initiative in 2014 to construct China's Standards of English Language Ability (CSE) as part of a broader effort to establish the country's own Foreign Language Proficiency Assessment System. Released in April 2018, the CSE is the first evaluation system for English language ability in China, and defines three stages of English language ability, 
namely, elementary, intermediate, and advanced, with nine levels on the aggregate. These levels cover students' educational backgrounds from elementary school to university, thus providing a unified testing system for Chinese English language learners and users. To promote cooperation and mutual recognition between the English tests in China and those that are better known globally, the British Council, along with China's Ministry of Education, published the results of their collaborative research on the successful link of IELTS and Aptis to CSE on the 15th of January, 2019 (the British Council, 2019). This was a milestone achievement in China's English language teaching and assessment, and more importantly, it represents an important step in merging China's English proficiency scale into the international examination system. Combining linguistic theory, empirical evidence, and teacher-student feedback, CSE holds promise as an effective assessment framework that will advance EFL education in China and globally.

Therefore, the article begins with an introduction to the rationale behind and the formulation process of the CSE, before presenting a detailed description of its content. Next, some dominant language proficiency scales in the world were reviewed and their unique characteristics were highlighted. Then the comparisons of CSE and the existing scales were enumerated. This was followed by an account of the recent linking of IELTS and Aptis to CSE, along with its possible implications. Finally, the future development of CSE at home and abroad in the global context were discussed.

\section{CSE in China: Rationale, Content, and Application}

The search for a common language assessment metric is considered "essential for the development of a meaningful national language policy in foreign language learning and use" (Lambert, 1993, p. 155). However, China has lagged far behind other countries in developing such a common framework scale. It is not until the early 2000s that a host of scholars and language experts in mainland China began to realize this problem, and later proposed the establishment of CSE to systemize China's foreign language assessment system, as can be seen in their publications in some leading Chinese journals (Han, 2006; Jin \& Wu, 2014; Jing, Li, Chen, Li, \& $\mathrm{Hu}, 2015$; Yang \& Gui, 2007). The development and ultimate release of the CSE scale is the culmination of years of efforts to achieve this goal.

In designing such a scale, the National Education Examinations Authority at China's Ministry of Education played a central role in coordinating the work of various departments, and established a panel of experts to oversee the entire process, with different subgroups in charge of different aspects of the scale design, such as listening comprehension and writing. There are three steps that characterize this process. Step 1 is the collection of descriptors based on a search of the relevant literature, sampling of teaching practices, and typical language activities. Step 2 is to classify these descriptors based on a combination of expert judgements and those of in-service teachers. Step 3 is to scale the descriptors using questionnaire results and statistical techniques for validation and other purposes. To ensure that the scale is scientific, practical and operational, the CSE was based on Bachman's communicative language competence framework (Bachman, 1990) and took a use-oriented approach by using "can-do" descriptions to define what specific tasks language learners and users can perform in real-life contexts.

As the first evaluation system for English language ability in China, the CSE framework scales language learners and users at an ascending series of nine levels, with each three levels corresponding to one stage (levels 1-3 to the elementary stage, levels $4-6$ to the intermediate stage, and levels 7-9 to the advanced stage) (for the general architecture, see Table 1). Under this general architecture, a descriptive framework is formulated to define different aspects of the learners' language abilities, which include language comprehension, language expression, pragmatic ability, linguistic knowledge, translation and interpreting, and language use strategies. Each of these aspects can be subcategorized to encompass more detailed information. Take language comprehension for example. It bifurcates into listening comprehension and reading comprehension, which is further divided into oral/written description, oral/written narration, oral/written exposition, oral/written argumentation, oral/written instruction, and oral/written interaction, respectively. Based on the general architecture and the descriptive frameworks, the EFL learners and users' overall English ability and their ability in each aspect are described in detail using "can-do" descriptors (Ministry of Education of the People's Republic of China, 2018). The general scale defining the overall language ability of Chinese English language learners and users is presented graphically in Figure 1. 
Table 1. The three stages with nine levels of China's standards of English language ability

\begin{tabular}{ll}
\hline English Language Ability Development Stage & Level \\
\hline Advanced stage & Level 9 \\
& Level 8 \\
& Level 7 \\
Intermediate stage & Level 6 \\
& Level 5 \\
Elementary stage & Level 4 \\
& Level 3 \\
& Level 2 \\
& Level 1 \\
\hline
\end{tabular}

Devising such a proficiency scale has implications for multiple stakeholders, and may serve to bridge three key aspects of EFL education in China: language learning, language teaching, and language assessment. For language learners, they can judge their own relative English ability with reference to the scales, and make study plans accordingly. They can also choose the most appropriate learning materials, assess their own learning process, and sign up for proficiency tests that best meet their needs. In terms of language teaching, educational institutions may tap into the information on the scales, such as the learners' needs, motivations and personalities, to design tailor-made instructions. It can also assist teachers in curriculum design and setting attainable teaching goals. As to language assessment, both language teachers and educational institutions can design language assessment projects to evaluate their own teaching, and develop more appropriate tests based on such scales. Finally, as one key aspect of CSE is to link with renowned international English tests, the release of CSE may help merge China's language assessment into the international evaluation system, thus extending the influence of CSE to the rest of the world.

\section{Influential Language Proficiency Scales in the World}

Modern research on the development of different language proficiency scales has had a fairly long history, spanning approximately 60 years (Han, 2006; Ounis, 2017). Most of the research is concentrated in areas like North America, Australia, and western Europe. But the resulting scales developed have often transcended national boundaries and become widely applied in many parts of the world.

As early as the 1950 s, the U.S. became the first country in the world to develop a language proficiency scale aimed at assessing the oral abilities of its military personnel stationed overseas. Developed by Foreign Service Institute in 1955, this scale came to be known as the FSI scale. It was originally composed of six main levels, with a plus level between each two levels, thus culminating in a 11-point scale ranging from No Proficiency to Functionally Native Proficiency. Due to its huge influence, this scale was later utilized by other agencies of the government, such as CIA and FBI, thus adopting the name the Interagency Language Roundtable Scale (ILR). In the 1980s, it was expanded to include not only the speaking dimension, but also listening, reading and writing (Herzog, 2006). The official guidelines for the ILR were ratified and put into use in 1985. Two advantages characterize the FSI scale. First, the format of one-on-one discussion between the examiner and the examinee was adopted for the first time as a way to assess the examinees' oral proficiency. The test method Oral Proficiency Interview (OPI) also became the most important and certified test nationwide. Second, FSI was an exemplar for later language proficiency scales as it initiated the use of descriptors to define a person's oral ability in real-life contexts. However, the FSI scale also has its problems. For example, it does not provide descriptions of a person's overall language ability, and the gradations between the elementary and intermediate levels were not balanced.

As an immigrant country, Canada also has its own proficiency scale called the Canadian Language Benchmarks (CLB). This scale was developed partly as a policy initiative to increase the new immigrants' adaptability to the new environment, and partly to dispel the confusion of the testing market in Australia (Fleming, 2015). Released in 2000, CLB comprises three levels from elementary, intermediate, to advanced, with each level covering listening, speaking, reading and writing. According to the CLB scale, each level comprises three aspects of information: global performance descriptors, performance conditions, and competency outcomes and standards. Global performance descriptors are descriptions of language learners' ability in listening, speaking, reading, and writing. Performance conditions specify the communicative goal, language contexts, interlocutors, topics, and the length of the tasks in question. Competency outcomes and standards provide representative examples of tasks that language learners at a certain proficiency level are capable of performing. What is special about this model is that it is based on the communicative language competence framework, thus reflecting the latest research results from second language acquisition and language testing. 


\begin{tabular}{|c|c|c|}
\hline CSE Levels & & Descriptors for English language ability at this level \\
\hline \multirow[t]{2}{*}{ CSE 9} & $>$ & $\begin{array}{l}\text { Can accurately and thoroughly understand a large variety of language } \\
\text { materials. }\end{array}$ \\
\hline & $>$ & $\begin{array}{l}\text { Can easily use all manner of expressions to engage in in-depth verbal } \\
\text { communication with others on all kinds of topics; can express him/herself } \\
\text { precisely, naturally, idiomatically, and in a particular style. }\end{array}$ \\
\hline \multirow[t]{2}{*}{ CSE 8} & $>$ & $\begin{array}{l}\text { Can understand different types of language materials on a variety of topics; } \\
\text { can comprehend the message and recognise discourse features and } \\
\text { linguistic style. }\end{array}$ \\
\hline & $>$ & $\begin{array}{l}\text { Can skilfully use varied manner of expressions to communicate with others } \\
\text { tactfully and effectively on an academic or specialised topic on a variety of } \\
\text { occasions; can accurately, appropriately, and fully explain, justify, and } \\
\text { comment on a range of related topics; can express him/herself precisely, } \\
\text { fluently, coherently, and appropriately. }\end{array}$ \\
\hline \multirow[t]{2}{*}{$\operatorname{CSE} 7$} & $>$ & $\begin{array}{l}\text { Can understand language materials on a range of topics, including those } \\
\text { related to his/her field of specialisation; can accurately identify the theme } \\
\text { and key points of the material, objectively assess and comment on its } \\
\text { content, and understand its deeper meaning. }\end{array}$ \\
\hline & $>$ & $\begin{array}{l}\text { Can engage in in-depth discussion and exchange with others on a range of } \\
\text { related academic and social topics; can effectively describe, clarify, } \\
\text { explain, justify, and comment on such matters and express him/herself } \\
\text { clearly, appropriately, smoothly, and in a conventional manner. }\end{array}$ \\
\hline $\operatorname{CSE} 6$ & $>$ & $\begin{array}{l}\text { Can understand language materials on a range of topics (including subjects } \\
\text { of a more general nature) and fully grasp their key points and logical } \\
\text { relationships; can analyse, determine, and evaluate viewpoints, attitudes, } \\
\text { and implicit meanings therein. }\end{array}$ \\
\hline
\end{tabular}

$>$ Can discuss a range of familiar topics in academic and work interactions, effectively present information about, compare, and comment on different ideas, and express his/her own opinions; can express him/herself coherently, appropriately, smoothly, and in keeping with relevant stylistic conventions and the features of a particular register of language.

CSE $5>$ Can understand language materials on general topics discussed in a variety of situations; can grasp their theme, identify the key points, find out facts, views, and intricate details, and get to know the intentions and attitudes of others.

$>$ Can communicate, discuss, and negotiate with others on topics such as study and work in familiar situations and express his/her viewpoints and display his/her attitude; can describe, clarify, or explain matters on general topics relatively effectively and express him/herself accurately, coherently, and appropriately.

CSE $4>$ Can understand language materials on common topics discussed in normal social interactions; can identify main themes and key content, grasp the main facts and viewpoints, and understand the intentions and attitudes of others.

$>$ Can communicate with others on familiar subjects in familiar situations; can describe the development of an event, describe current situations and related activities, point out the main features of things, and briefly discuss his/her viewpoints; can express him/herself fairly accurately, clearly, and coherently.

CSE $3>$ Can understand simple everyday language materials, glean specific or key information from them, identify key points, and deduce the intentions of others.

$>$ Can communicate with others in routine or normal social interactions using simple language; can describe personal experiences and aspirations and clearly present hisher reasons and viewpoints; can express him/herself with a basic level of accuracy, coherence, and fluency.

CSE $2>$ Can understand simple and commonly found everyday language materials, glean basic factual information from them, and grasp their main content.

$>$ Can communicate with others in simple terms on familiar topics or matters of immediate relevance; can present information, narrate events, and describe circumstances; can make clear his/her basic intentions and achieve the basic goals of an interaction.

CSE $1>$ Can understand simple and frequently used language materials, recognise basic information regarding related activities or matters of immediate relevance, and understand the meaning of basic terms.

$>$ Can use short and simple discourse to greet and interact with others, introduce him/herself and others, describe the basic properties of matters of immediate relevance, and express his/her opinions; occasionally may resort to repetition, gesticulation, or other non-linguistic means to aid interactions.

Figure 1. Overall English language ability as defined in China's standards of English ability 
The most well-known and widely applied proficiency scale is perhaps the Common European Framework of Reference for Languages: Learning, teaching, and assessment (CEFR). It is a common framework used in all European regions, serving an important function in language teaching, language learning, and language assessment. The designers of this framework took an action-oriented approach in delineating the language learners' language use and learning (North, 2000). In this process, they defined the learners as active social agents, who can mobilize their communicative language abilities to fulfil different tasks using the appropriate strategies. The language tasks were defined as output tasks, input tasks, and agency tasks (North, 2000). CEF categorizes language abilities into three strata, including elementary, intermediate, and advanced, which corresponds to A1, A2, B1, B2, C1, and C2, with A1 indicating the lowest level and $\mathrm{C} 2$ the highest. CEF is comprehensive in that it not only provides global performance descriptors for a language learner or user's language ability, but also provides descriptors at each level and regarding each task. In that sense, CEF is multidimensional and stratified. Other advantages that characterize CEF is the systematic combination of real-life experience and quantitative and qualitative approaches in its design, which makes the framework more comprehensive and trustworthy.

Other commonly used proficiency scales include those designed by American Council on the Teaching of Foreign Languages (ACTFL), Association of Language Testers in Europe (ALTE), and the International Second Language Proficiency Ratings (ISLPR), among others.

\section{Comparisons of CSE with Existing Proficiency Scales}

Despite the widespread use of the above scales and others, there are also problems connected to them. For example, some scales (e.g., ACTFL, CLB) have not been empirically tested (Alhussain, 2019; Tigchelaar, Bowles, Winke, \& Gass, 2017), and thus may raise reliability and validity concerns. Even CEFE, as authoritative as it is, has been criticized by some scholars for taking a broad brush in its scaling process (Wisniewski, 2017).

Compared with these scales, CSE enjoys several advantages. First, it is clearly based on Bachman's (1990) communicative language competence framework, and draws on Anderson, Krathwohl and Bloom's (2001) redefinition of the cognitive domain as the intersection of the Cognitive Process Dimension and the Knowledge Dimension, which are represented as hierarchical steps. Different cognitive tasks thus serve to differentiate different communicative tasks in terms of their complexity. In this sense, CSE is more firmly grounded in existing theories than some other scales. Second, the descriptors of CSE refined the systematic approach by defining listening speed using quantitative values, providing a clear criterion for the scaling of different levels of listening difficulty. This was a step forward compared with CEFR, which does not have specified data to clearly define different levels of ability (Min, He, \& Luo, 2018). Third, the scaling of CSE descriptors in terms of their difficulty is based on a combination of teacher judgement and students' self-reporting in the form of questionnaires. The scores obtained from these questionnaires were analyzed using Rasch modelling, which would yield a specific value for each single descriptor and students' ability (Min, He, \& Luo, 2018). Thus, the decision to scale the descriptors was rooted in informed data collection and analysis, making the final products more reliable. In addition, CSE also distinguishes itself from current scales in that it focuses specifically on students in schools. Many of the international proficiency scales are designed for the general population, and thus may not be appropriate for certain learning situations or groups. With CSE, the student population is the main concern, reflecting both the reality of EFL education in China, and an effort to complement the existing scales.

\section{Going Global: Linking CSE to IELTS and Aptis}

As the first of its kind, the successful link of IELTS and Aptis to CSE marks a significant step towards making the CSE scale part of the global examination system, and promises more steps to come to make China's language testing part of a global enterprise.

The results of this linking are presented as a juxtaposition of the cut scores of IELTS and Aptis and their corresponding levels on the CSE scale. According to the results, a score of 6 in IELTS reading is commensurate with CSE level 6, a score of 7 in IELTS speaking is equivalent to CSE level 8, while a score of 14 in Aptis listening corresponds to CSE level 3. Once IELTS scores reach 6 or higher, they are equal to the corresponding CSE levels. A detailed chart displaying the corresponding scores is listed in Figure 2 and Figure 3. 


\begin{tabular}{|c|c|c|c|c|c|}
\hline CSE Level & CSE Level 4 & CSE Level 5 & CSE Level 6 & CSE Level 7 & CSE Level 8 \\
\hline IELTS Score & & & & & \\
\hline Total Score & 4.5 & 5.5 & 6 & 7 & 8 \\
\hline Listening & 5 & 6 & 6.5 & 7.5 & 8.5 \\
\hline Reading & 4.5 & 5.5 & 6 & 7 & 7.5 \\
\hline Speaking & 5 & 5.5 & 6 & 6.5 & 7 \\
\hline Writing & 4 & 5 & 6 & 7 & 7.5 \\
\hline
\end{tabular}

Notes:

1. CSE is short for China's Standards of English Language Ability, which includes 9 levels. This research focuses on CSE Levels 4 to 8 .

2. The IELTS score is reported with a total score (an average of the scores achieved across the four skill papers) and scores for each of the four skills, i.e. listening, reading, speaking and writing. All scores are between 1 and 9 , with 0.5 as the minimal unit.

3. This table displays the cut scores of the IELTS test mapped to CSE levels. For example, a score of 5 in IELTS listening is equivalent to CSE level 4; a score of 5.5 in IELTS reading is equivalen to CSE level 5; a score of 6 in IELTS speaking us equivalent to CSE level 6.

Figure 2. Results of linking IELTS to China's standards of English language ability

\begin{tabular}{|c|c|c|c|c|c|}
\hline CSE Level & CSE Level 3 & CSE Level 4 & CSE Level 5 & CSE Level 6 & CSE Level 7 \\
\hline Listis Score & 14 & 21 & 29 & 37 & 43 \\
\hline Reading & 16 & 26 & 35 & 42 & 46 \\
\hline Speaking & 21 & 29 & 37 & 43 & 47 \\
\hline Writing & 22 & 31 & 39 & 45 & 50 \\
\hline
\end{tabular}

Notes:

1. CSE is short for China's Standards of English Language Ability. This research focuses on CSE Levels 3 to 7 .

2. The Aptis score includes scores of four sections, i.e. listening, reading, speaking and writing. All scores are between 0 and 50 .

3. This table displays the cut scores of the Aptis test mapped to CSE levels. For example, a score of 14 in Aptis listening is equivalent to CSE Level 3; a score of 29 in Aptis speaking is equivalent to CSE Level 4; a score of 45 in Aptis writing is equivalent to CSE Level 6.

Figure 3. Results of linking Aptis to China's standards of English language ability

Linking IELTS and Aptis to CSE has great significance both by itself and for the wider community. As Bachman (1990, p. 5) long noted, the search for a common language assessment metric is a common thread running throughout much of the literature on language testing. This latest effort in linking different tests represents another step towards that end, that is, the creation of an internationally recognized common framework. This would smooth the transition of students across educational programs and cultures. In the global context where IELTS and TOEFL predominate as certified criteria for assessing students' English language ability, which is often a prerequisite for admission to or rejection by a program, linking CSE to these tests would reduce the number of tests students have to take and make their results more comparable on different occasions. Besides, promoting mutual recognition between these tests can enhance strategic cooperation between educational institutions and government agencies, which can lead to more student exchanges and growing demands for English testing. The reciprocal benefits of this link are obvious. 


\section{Future Development of CSE in a Global Context}

One crucial step following the release of the CSE scale is to design its corresponding language tests based on such a scale. A brief overview of the major language proficiency scales in the world suggests that they are all accompanied by their respective tests. The FSI scale, for example, is applied in language testing in the form of the Oral Proficiency Interview (OPI). The CLB scale is accompanied by the Canadian Language Benchmarks Assessment (CLBA). In China, where English language teaching and learning is assigned paramount importance, there has been a diverse array of language tests designed for various purposes. Each of these tests may be built on a distinct language assessment framework. In most cases, however, there is no clear theoretical underpinning for such tests (Cheng, 2008). Commonly used English language tests include CET Band 4, CET Band 6, TEM 4, TEM 8, etc., representing a confusing language testing market. To dispel this confusion, it is imperative for the government and other authorities to design a test based on the CSE scale, which must be widely applicable so as to meet the diverse needs of test takers in China's language learning market. As China deepens its reform in education, this would improve fairness and efficiency in recruiting students to colleges and universities, stem the proliferation of language tests in the market, and provide a common metric for multiple stakeholders in the testing process. And with China opening up more and more to the rest of the world, such a step would also help cultivate a new generation of capable language learners and users who will rise up to the challenges of the 21 st century, which could contribute to China's standing and representation in the global landscape.

Another important step is to increase the connectivity of CSE to the global examination system. With IELTS and Aptis already linked to China's CSE, China has made significant strides in merging its language proficiency standards into this system. The next step, according to the authorities on this subject, is to link TOEFL to China's CSE. This would consolidate the status of CSE in the global examination market, and juxtapose these different tests to warrant a direct comparison. As transnational and intercultural communication becomes the rule of the day, student exchanges are expected to become commonplace. As long as English remains the global lingua franca it is today, English language testing is inevitable. Whether students take one test or another, or they use the results of one test in comparison to those of another test, this would require a comparable relationship between different tests.

Language tests are never for testing purposes only. Instead, they carry social, economic, and political implications for all those involved in the testing process. CSE's link with other tests in the world thus holds promise to deepen China's ties to other countries in many aspects, such as educational cooperation, economic partnerships, and beyond.

\section{Conclusion}

This article sketched the internationalization of China's Standards of English Language Ability Assessment as it took shape in China and became assimilated into the global examination system. An introduction was first given to the rationale behind its design, the content of the scale, and its possible applications in language learning, language teaching, and language assessment. Some of the major language proficiency scales in the world were then presented and evaluated regarding their unique characteristics, with the goal of providing a historical context for viewing CSE in perspective. The successful link of IELTS and Aptis to CSE was discussed with reference to the linking results and its possible implications. Future development of CSE was also brought into focal attention by highlighting its possible trajectory in the global context. As an initial step for China to engage with the world, the development of CSE and its link with IELTS and Aptis has wider relevance to many other forms of international communication between China and other countries in the future.

\section{Acknowledgments}

The authors gratefully acknowledge the research support provided by the Philosophical and Social Sciences Planning Project of Zhejiang Province in 2020 [grant number 20NDJC01Z], the second batch of 2019 Industry-University Collaborative Education Project of Chinese Ministry of Education [grant number 201902016038], the Fundamental Research Funds for the Central Universities of Zhejiang University, the Teaching Reform Research Projects in the 13th Five Year Plan of Higher Education of Zhejiang Province, Student Research Practice Program [grant number P2020015], and Information Technology Center, Zhejiang University.

\section{References}

Alhussain, A. M. (2019). Introducing and testing a measurement tool for English language proficiency: Aisha's tool. International Journal of English Linguistics, 9(3), 319-329. https://doi.org/10.5539/ijel.v9n3p319

Anderson, L. W., Krathwohl, D. R., \& Bloom, B. S. (2001). A taxonomy for learning, teaching, and assessing: A 
revision of Bloom's taxonomy of educational objectives. New York: Longman.

Bachman, L. F. (1990). Fundamental considerations in language testing. Oxford: Oxford University Press.

Bolton, K., \& Graddol, D. (2012). English in china today. English Today, 28(3), 3-9. https://doi.org/10.1017/S0266078412000223

Chen, J., Zhang, Y., \& Hu, J. (2020). Synergistic effects of instruction and affect factors on high- and low-ability disparities in elementary students' reading literacy. Reading and Writing: An Interdisciplinary Journal. https://doi.org/10.1007/s11145-020-10070-0

Chen, J., Zhang, Y., Wei, Y., \& Hu, J. (2019). Discrimination of the contextual features of top performers in scientific literacy using a machine learning approach. Research in Science Education. https://doi.org/10.1007/s11165-019-9835-y

Chen, X., \& Hu, J. (2019). Evolution of U.S. presidential discourse over 230 Years: A psycholinguistic perspective. International Journal of English Linguistics, 9(4), 28-41. https://doi.org/10.5539/ijel.v9n4p28

Chen, X., \& Hu, J. (2020). ICT-related behavioral factors mediate the relationship between adolescents' ICT interest and their ICT self-efficacy: Evidence from 30 countries. Computers \& Education, 159, 104004. https://doi.org/10.1016/j.compedu.2020.104004

Cheng, L. (2008). The key to success: English language testing in China. Language Testing, 25(1), 15-37. https://doi.org/10.1177/0265532207083743

Cheng, L., \& Curtis, A. (Eds.). (2010). English language assessment and the Chinese learner. New York: Routledge. https://doi.org/10.4324/9780203873045

Council of Europe. (2001). Common European framework of reference for languages: learning, teaching, and assessment. Cambridge: Press Syndicate of the University of Cambridge.

Fleming, D. (2015). Citizenship and race in second-language education. Journal of Multilingual and Multicultural Development, 36(1), 42-52. https://doi.org/10.1080/01434632.2014.892500

Han, B. C. (2006). A review of current language proficiency scales. Foreign Language Teaching and Research, 6, $443-450,480$.

Herzog, M. (2006). An overview of the history of the ILR language proficiency skill level descriptors and scale. Retrieved from http://www.govtilr.org/skills/irl scale history.htm

$\mathrm{Hu}$, J. (2014). An analysis of the design process of a language learning management system. Control and Intelligent Systems, 42(1), 80-86. https://doi.org/10.2316/Journal.201.2014.1.201-2534

Hu, J., Chen, K. Z., \& Liu, D. F. (2020). Chinese university faculty members' visiting experience and professional growth in American universities. Social Behavior and Personality: An International Journal, 48(5), e7898. https://doi.org/10.2224/sbp.7898

Hu, J., \& Wei, Y. E. (2019). The centrality of creativity: A new perspective on English language teaching. English Today, 35(2), 60-61. https://doi.org/10.1017/S0266078418000299

Jin, Y., \& Wu, Z. M. (2014). Developing the common Chinese Framework of Reference: Challenges at macro and micropolitical levels. Paper presented at the 36th Language Testing Research Colloquium, VU University Amsterdam, the Netherlands.

Jing, Y., Li, B., Chen, N., Li, X., \& Hu, J. (2015). The discrimination of learning styles by bayes-based statistics: An extended study on ILS system. Control and Intelligent Systems, 43(2), 68-75. https://doi.org/10.2316/Journal.201.2015.2.201-2666

Kunnan, A. J. (2014). Preface: English in East Asia: Teaching, learning and assessing. In D. D. Qian \& L. Li (Eds.), Teaching and learning English in East Asian universities: Global visions and local practices (pp. 911). Newcastle upon Tyne: Cambridge Scholars Publishing.

Lambert, R. (1993). Foreign Language Competency. In S. J. Moore \& C. A. Morfit (Eds.), Language and international studies: A Richard Lambert perspective (pp. 150-161). Washington D.C.: National Foreign Language Center Monograph Series.

Min, S. C., He, L. Z., \& Luo, L. (2018). Validation of listening descriptors of China's Standards of English: An analysis of self-assessment data using polytomous IRT models. Foreign Languages in China, 15(2), 72-81. https://doi.org/10.13564/j.cnki.issn.1672-9382.2018.02.010 
Ministry of Education of the People's Republic of China. (2018). China's Standards of English Language Ability. Retrieved from http://www.moe.gov.cn/srcsite/A19/s229/201804/t20180416_333315.html

North, B. (2000). The development of a common framework scale of language proficiency. New York: Peter Lang. https://doi.org/10.3726/978-1-4539-1059-7

Ounis, A. (2017). The assessment of speaking skills at the tertiary level. International Journal of English Linguistics, 7(4), 95-112. https://doi.org/10.5539/ijel.v7n4p95

Qian, D. D., \& Cumming, A. (2017). Researching English language assessment in china: Focusing on high-stakes testing. Language Assessment Quarterly, 14(2), 97-100. https://doi.org/10.1080/15434303.2017.1295969

The British Council. (2019). Collaborative research on linking IELTS and Aptis to China's Standards of English Language Ability. Retrieved from https://www.britishcouncil.cn/en/cse/about-new

Tigchelaar, M., Bowles, R. P., Winke, P., \& Gass, S. (2017). Assessing the validity of ACTFL can-do statements for spoken proficiency: A Rasch analysis. Foreign Language Annals, 50(3), 584-600. https://doi.org/10.1111/flan.12286

Wisniewski, K. (2017). Empirical learner language and the levels of the Common European Framework of Reference. Language Learning, 67, 232-253. https://doi.org/10.1111/lang.12223

Xiao, Y., Liu, Y., \& Hu, J. (2019). Regression analysis of ICT impact factors on early adolescents' reading proficiency in five high-performing countries. Frontiers in Psychology, 10, 1646. https://doi.org/10.3389/fpsyg.2019.01646

Yang, H. Z., \& Gui, S. C. (2007). On establishing a unified Asian level framework of English language proficiency. Foreign Languages in China, 2, 34-37, 64.

\section{Copyrights}

Copyright for this article is retained by the author, with first publication rights granted to the journal.

This is an open-access article distributed under the terms and conditions of the Creative Commons Attribution license (http://creativecommons.org/licenses/by/4.0/). 